\title{
A Etnoarqueologia no Brasil: ciência e sociedade no contexto da redemocratização
}

\author{
Rita Juliana Soares Poloni*
}

POLONI, R.J.S. A Etnoarqueologia no Brasil: ciência e sociedade no contexto da redemocratização. Revista do Museu de Arqueologia e Etnologia, São Paulo, 19: 87-102, 2009.

Resumo: O presente trabalho buscou investigar as perspectivas teórico-metodológicas empregadas em trabalhos em Etnoarqueologia, publicados no Brasil a partir da década de 1980. Para tanto foram analisadas teses e dissertações com o objectivo de delas extrair as metodologias empregadas e o campo teórico que as embasa, bem como de construir um quadro representativo da actuação deste campo científico no Brasil. Percebeu-se o forte embasamento histórico e político dessas pesquisas bem como sua preferência por abordagens metodológicas e técnicas mais generalistas na análise dos seus objetos de estudo.

Palavras-chave: Etnoarqueologia - Arqueologia - Teoria - Métodos Sociedade - Brasil.

\section{Introdução}

F ste artigo tem por objectivos a investi gação das perspectivas teóricometodológicas de alguns textos científicos em Etnoarqueologia, publicados no Brasil, a partir da década de 1980, bem como de suas implicações sócio-políticas, levando necessariamente à expectativa da construção de um quadro teórico que, sendo estritamente relacionado com as concepções - explicitas ou não - desta ciência, presentes nas pesquisas a serem analisadas, teve por objectivo caracterizar este campo científico no contexto do Brasil Contemporâneo.

${ }^{*}$ ) Universidade do Algarve, Portugal. <julianapoloni@hotmail.com>
Abordar um tema que se insere no contexto científico e social brasileiro é por um lado um grande desafio, e por outro, uma interessante oportunidade de pensar questões quotidianas de uma nova maneira. Por outro lado, investigar as relações entre ciência e sociedade, ou ainda, as imbricações entre as diversas abordagens da Etnoarqueologia e os objetivos científicos da Arqueologia de modo geral, é uma forma de compreender não só os horizontes teórico-metodológicos desse campo científico no contexto sóciopolítico brasileiro, mas também uma forma de buscar ampliar o conhecimento acerca das relações entre diversas perspectivas de uma mesma ciência ou desta com condicionantes sociais e políticos do contexto no qual seus pesquisadores se inserem. 


\section{Da definição do tema}

Ao tentar compreender a relação existente entre a produção artefatual humana e o meio no qual determinada comunidade se insere ou a relação existente entre esta produção e a geração de conhecimento, significado, identidade ou poder para tais comunidades, o trabalho do arqueólogo está sempre em alguma medida ligado à analogia. Como tentar compreender o significado ou função de determinado artefacto sem haver alguma correlação entre este e outros já conhecidos? Ou, como tentar apreender a importância destes artefactos para as suas comunidades produtoras e/ou consumidoras, ou o contexto social e ideológico nos quais esses mesmos artefactos são produzidos, reproduzidos, valorizados e divulgados, sem haver nenhuma referência, por menos generalizável que seja, de contextos em alguma medida semelhantes?

É neste ponto que a Etnoarqueologia toma importância num cenário científico que se abre às possibilidades de conhecer comunidades humanas que vivem - ou que já viveram - sob contextos sociais e ecológicos largamente diversos do modo de vida Ocidental, criando analogias que sirvam não só para o conhecimento arqueológico destes próprios povos como de outros a respeito dos quais, possam servir em alguma medida, de parâmetro comparativo.

Definida como uma subdisciplina da Arqueologia, a Etnoarqueologia tem como campo de estudo:

“(...) la producción, tipología, distribución, consumo, y descarte de la cultura material, con especial referencia a los mecanismos que relacionan variabilidad y la variación al contexto sociocultural y a la inferencia de los mecanismos de procesos del cambio cultura." (Politis 2002: 68).

É esta preocupação com a relação existente entre produção material e contexto sociocultural que leva os Etnoarqueólogos a se dedicarem ao estudo de comunidades "indígenas" ${ }^{1}$ vivas, para daí inferirem conhecimentos de cunho arqueológico, que relacionem a produção artefactual aos diversos contextos nos quais são produzidos.

Neste ponto o Brasil torna-se um país de grande interesse para esse campo de estudo. Por possuir, dentro de seu território, centenas de comunidades indígenas a viverem em maior ou menor grau de isolamento em relação à cultura Ocidental, este país se apresenta como potencial área de interesse para essa disciplina.

Por outro lado, como a Etnoarqueologia mergulha no estudo de grupos étnicos (em sua relação com a produção material humana), se vê participante na trama político-social que envolve tal temática nas sociedades contemporâneas, ou seja, na importância das etnias na construção, conservação, e transformação das ideias de Nação e na implicância que estas têm na discussão da relação dominantes/dominados, colocando tais estudos em situações diversas de abrangência, enfoque, ou liberdade de acção, mediante a situação político-social dos países nos quais essas pesquisas se desenvolvem.

Em relação a esse contexto, o Brasil é uma Nação que tem a questão étnica como componente ideológica de entendimento de sua própria identidade. Fortemente marcada pela presença das etnias indígenas, africanas e europeias, esta Nação se vê, desde os tempos coloniais, chamada a dialogar com estes universos culturais, e o faz, no decorrer do tempo, sob diferentes perspectivas.

Particularmente, a partir da década de 1980, quando o Brasil passa a mergulhar no contexto da redemocratização pós Ditadura Militar (1964-1985) tais questões passam a tomar um novo fôlego e a ser amplamente (re)discutidas não só em âmbito científico, mas também nas esferas políticas e sociais desse país.

Torna-se, então, interessante questionar de que forma a Etnoarqueologia, enquanto campo

(1) Indigena - Termo originário da palavra latina Indigenae - (indu - reforço de in - geno). Adj. Indígena, do país. Subs. M . indígena, natural do país (Ferreira1996), ou ainda: Que é originário de determinado país, região ou lugar; ABORÍGINE; NATIVO [Antôn.: alienígena] (Aulete; Valente 2007) 
teórico-metodológico da Arqueologia, é recebida pelo universo científico brasileiro a partir da década de 1980, período em que se dá a redemocratização do Brasil e que se ampliam no país as discussões a respeito dos princípios da Escola Processualista e Contextualista, que estão nas raízes da Etnoarqueologia como campo científico, tanto em âmbito nacional quanto internacional.

Da mesma forma, torna-se igualmente importante acompanhar como esta abordagem arqueológica tem tomado dimensão social e política na actualidade, ou seja, como tal universo teórico-científico imbrica-se com as questões étnico-sociais que suscita e sua penetração no seio da sociedade como instrumento de questionamentos a respeito do tema.

\section{Dos objetos de estudo}

Como objeto desta pesquisa foram escolhidas sete teses científicas, sendo quatro de Mestrado e três de Doutorado, escritas entre os anos de 1993 até 2007. São elas, respectivamente, Sem Tekohá não há Tekó: Em Busca de um Modelo Etnoarqueológico da Aldeia e da Subsistência Guarani e sua Aplicação a uma Área de Dominio no Delta do Rio Jacui-RS (1993), A Produção Cerâmica como Reafirmação de Identidade Étnica Maxakali: Um Estudo Etnoarqueológico (1999), Cenários da Ocupação Guarani na Calha do Alto Paraná: um Estudo Etnoarqueológico (2001), Organização e Uso do Espaço em duas Aldeias Xerente: Uma Abordagem Etnoarqueológica (2003), A Tecnologia e seus Significados. Um Estudo da Cerâmica dos Asuriní do Xingu e da Cestaria dos Kayapó-Xikrin sob uma Perspectiva Etnoarqueológica (2000), Etnoarqueologia dos Grafismos Kaigang: Um Modelo para a Compreensão das Sociedades Proto-Jê Meridionais (2001) e Os caçadores Ceramistas do Sertão Paulista: Um Estudo Etnoarqueológico da Ocupação Kaingang no Vale do Rio Feio/Aguapei (2007). A escolha destas pesquisas se deu conforme critérios de visibilidade quanto à sua divulgação científica, e clara manifestação de enquadramento dentro dos universos teóricos e metodológicos da Etnoarqueologia.
Evidentemente, estes trabalhos não representam a totalidade daqueles escritos dentro dos horizontes teóricos desse campo científico, e nem foi objetivo desta pesquisa pretender uma abrangência total desses trabalhos durante o período proposto, mas, sendo um trabalho qualitativo, buscou através da análise da amostra escolhida tentar traçar alguns encaminhamentos teóricos e metodológicos da Etnoarqueologia brasileira nas últimas décadas.

Como forma de interpretação das teses e dissertações escolhidas, foram utilizados alguns marcadores ou questões, que serviram de orientadores de análise desses trabalhos, ou seja, definiram os conteúdos a serem pesquisados no texto, buscando equiparar os objetos de estudo na totalidade das pesquisas estudadas, a fim de estabelecer comparações entre essas pesquisas, a respeito das presenças e ausências de enfoque nos tópicos escolhidos.

Parte desses marcadores ou questões foram extraídos do livro "Ethnoarchaeology in Action" (David \& Kramer 2001:70), particularmente do terceiro capítulo desse livro, intitulado "Fieldwork and Ethics", e dizem respeito aos aspectos metodológicos e técnicos do trabalho em Etnoarqueologia considerados como necessários para o desenvolvimento de pesquisas dentro desse campo teórico, e que, portanto, deveriam estar claramente definidos nesses trabalhos. Tais tópicos são assim identificados:

\section{Contexto da pesquisa}

1- Localização e contexto histórico e cultural do grupo estudado.

Contexto político da pesquisa, incluindo situação do pesquisador, condições de financiamento e duração do trabalho de campo.

Conhecimentos do investigador, incluindo competências linguísticas, do grupo a ser pesquisado e da sua linguagem.

\section{Métodos etnográficos e técnicas}

1- Amostragem do grupo

a) Estratégias

Número de povoações, famílias ou indivíduos 
b) Representação de classes, posições sociais, status, papéis ou géneros

2- Métodos de Pesquisa

a) Observação Participante

Entrevistas

Questionários

Outras, incluindo reconstituições e experiências

3- Assistentes (remunerados)

a) Qualificações e relacionamento com os informantes.

4- Informantes

a) Categorias e formas de recompensas.

\section{5- Registos}

a) Materiais escritos, fotografias, registos visuais e sonoros, materiais etnográficos, e outras amostras de material, com informações sobre localização e acesso.

A esses tópicos foram acrescentados mais alguns, de minha própria elaboração, concernentes aos aspectos teóricos dos trabalhos analisados e que buscaram, além de tentar perceber as preferências teóricas desses trabalhos, detectar o grau de explicitação e de importância dada a esses aspectos nessas pesquisas. São eles:

\section{Contexto teórico}

1- Opções teóricas da Pesquisa

a) Processualismo

b) Contextualismo

c) Ambos universos teóricos

c) Outros universos teóricos

d) Indefinida

2- Grau de Explicitação Teórica

a) Explicitação Directa

b) Explicitação Indirecta

3- Referências Teóricas

a) Referências directas

b) Referências indirectas

c) Ausência de referências
Dentro da perspectiva de análise aqui explicitada, procura-se compreender o conceito de Processualismo dentro do universo de análise dinâmica da produção material humana segundo o que preconiza Binford, ou seja:

"The behavioral model recognizes that behavior is the dynamics of adaptation. People draw upon a repertoire of cultural background and experience to meet changing or variable conditions in their environments, both social and physical. Our expectations, then, are for variability in the archaeological record to reflect a variety of different kinds of coping situations. Activities will vary with the particular adaptive situation of the group and the character of tasks being performed. We would therefore expect variability in the archaeological record to reflect these different situations" (Binford 1978:3).

Assim, para compreender as diferenças presentes nos registos arqueológicos é preciso compreender as complexidades do meio no qual foram gerados, e como esse meio funciona como um sistema a busca por novas experiências e conhecimentos que aperfeiçoem nossos instrumentos de apreensão e de descrição da realidade, como por exemplo, o trabalho etnoarqueológico, são necessários. Essas experiências constituirão uma ponte entre a produção artefatual humana e os contextos comportamentais e ecológicos nos quais essa produção foi gerada. Dessa forma, a abordagem Processualista da Etnoarqueologia buscará, através dos registos etnográficos recolhidos pelo arqueólogo, evidenciar regularidades interculturais que possam auxiliar na reconstrução do passado arqueológico humano e buscar constantes nos processos de transformações culturais (David \& Kramer 2002:23).

Por outro lado, o conceito de Contextualismo é analisado segundo a definição de Hodder do que seja a busca de significado para a produção artefatual humana, ou seja,

"The practical meaning of an item of material culture varies according to the context in which it is used although (...) the use of an item in one context is not independent of its use in others. (...) The evocative effect 
of a material symbol depends on context and the same item may be viewed from different contexts at the same time. Each person brings an individual understanding, a particular coping system to the perception and use of each artefact. (...) Ambiguity is thus a necessary and central part of symbolic process. Without it, individuals could not, from their different standpoints, agree to differ, they could not be competent (or incompetent) social actors, and they could not change the social world by changing the material world" (Hodder 1985:14-15).

Assim, se um símbolo material qualquer pode ter diferentes significados em contextos diversos, se cada pessoa possui um entendimento particular de cada artefacto, e se essas individualidades estão na base de seu próprio entendimento e definição em relação ao outro, ao seu próprio posicionamento no interior da sociedade e ao poder de transformação da cultura material e imaterial que cada indivíduo ou grupo exerce no seio da sociedade, então a busca pela compreensão dos significados particulares, desse universo simbólico que recobre cada produção artefatual humana, está na base do entendimento da própria sociedade e de seus registos arqueológicos, da mesma forma que as analogias etnográficas em arqueologia tomam importância na medida em que estejam focadas nos contextos subjetivos, nos significados, que subjazem o processo de produção material humana, buscando compreender suas particularidades e especificidades.

Cumpre salientar, entretanto, que a classificação do conteúdo das teses aqui analisadas, segundo a conformidade, ou não, com determinado ponto de análise escolhido, sobretudo no que diz respeito a interpretação do contexto teórico, Processualista ou Contextualista, em que são desenvolvidas as pesquisas, é, em última análise, fruto da interpretação particular da autora deste trabalho, podendo não ser condizente com a interpretação que os autores das obras aqui analisadas fazem desse trabalho em particular ou de sua produção científica de modo geral. A análise dos pontos escolhidos em sua particular interpretação tem antes por objetivo traçar parâmetros de compreensão que constituam uma proposta interpretativa que caracterize de que forma o trabalho em Etnoarqueologia se tem desenvolvido no Brasil no contexto pós a Ditadura Militar, seus contornos próprios, seus horizontes, seus enfoques, ou seja, busca caracterizar a Etnoarqueologia pensada e vivida por pesquisadores que merecem o mais profundo respeito, não só da Comunidade Científica mas de toda a sociedade, por aceitarem o desafio de se envolverem em contextos sociais, culturais, políticos e geográficos muito específicos, profundamente estranhos aos seus próprios, em contato com o "Outro", em busca de respostas para seus próprios desafios e para os da Ciência, gerando conhecimento, mas também fazendo um tipo de Política que busca conhecer esse "Outro", não para colonizá-lo, julgá-lo ou alijá-lo, mas que busca em seu conhecimento, o compreender de nossa própria humanidade tanto em seus aspectos múltiplos quanto em suas semelhanças.

\section{Dos resultados da pesquisa}

A partir da análise dos textos escolhidos foi possível traçar algumas características marcantes da Etnoarqueologia brasileira contemporânea. Assim, nota-se, como primeiro ponto de caracterização desse campo cientifico no Brasil, que este percorre caminhos que, aproximandoo com intensidade da Etno-História, busca, por um lado, reconstituir trajectórias históricas e culturais dos povos indígenas estudados, enfatizando suas próprias lógicas culturais, seus caminhos e opções; mas, por outro, pondo a claro interferências, limitações e transformações ocorridas a partir do contacto com a sociedade nacional. Sobre as características da Etnoarqueologia no Brasil, assim nos fala Politis:

"Esta tendencia busca entender los procesos de continuidad y cambio en contextos sociales especificos, mediante el uso complementario de la información etnográfica. Etnohistórica y arqueológica. De esta 
manera se propone que la continuidad cultural de la secuencia cronológica desde tiempos pre-hispánicos hasta el presente, en base a un "marcado conservatismo" no sólo en la organización espacial de las aldeas, sino también en la tecnología cerámica, la subsistencia y la localización de los asentamientos (...). De alguna manera, este tipo de Etnoarqueología está intimamente ligado a lo que podriamos llamar 'historia indigena"” (Politis 2002:76)

Percebe-se, então, nessas pesquisas um propósito de produzir uma lógica de continuidade entre história e produção material, enfatizando os componentes de ordem cultural, religiosa, e de mentalidade como ativos condicionantes da forma como se produz a realidade artefatual por esses povos. Assim, a história e a cultura dos povos está na raiz das suas escolhas na produção artefatual e na sua caracterização cultural bem como esses mesmos artefatos constituem materialização e reafirmação de sua própria história e cultura.

Dessa forma, há uma nítida e manifesta preocupação em tornar claro ao leitor que essas sociedades possuem suas próprias lógicas e histórias que não são em nada inferiores às da sociedade nacional, mas, ao contrário, que por detrás dos objetos que produzem, e da sua forma de interferirem no meio circundante, há uma riqueza cultural e uma complexidade cognitiva e significativa em nada menos complexa que aquela através das quais manifesta-se nossa própria sociedade, embora seja, naturalmente, profundamente diferente do modo de vida ocidental.

A respeito da intensidade dos componentes histórico-culturais na construção dessas teses, percebe-se maior enfase nesse aspecto ao comparar a relação entre o número de páginas totais do texto em si, e as páginas dedicadas a essa temática. Nota-se que mesmo apesar de variações significativas entre as teses, no que diz respeito ao item analisado, a presença da reconstituição histórica e cultural nessas pesquisas, é, de modo geral, bastante forte (Quadro 1).

Por outro lado, se estes trabalhos buscam sempre estabelecer estudos relacionados à organização espacial das aldeias, à tecnologia cerâmica, aos meios de subsistência e à localização de assentamentos, como nos alerta Politis (2002), e se verifica na análise das teses escolhidas para este trabalho, é bem verdade também que esses pesquisadores têm a consciência das limitações que enfrentam ao optarem fazer pesquisas em Etnoarqueologia no Brasil. Frequentemente citam a falta de estudos mais aprofundados a respeito dos povos indígenas no território brasileiro como uma das dificuldades enfrentadas na execução de seus trabalhos e como uma perspectiva não só a ser alcançada por seus próprios estudos, mas também como objectivo de todos os pesquisadores dessa mesma temática no Brasil (Tabela 1).

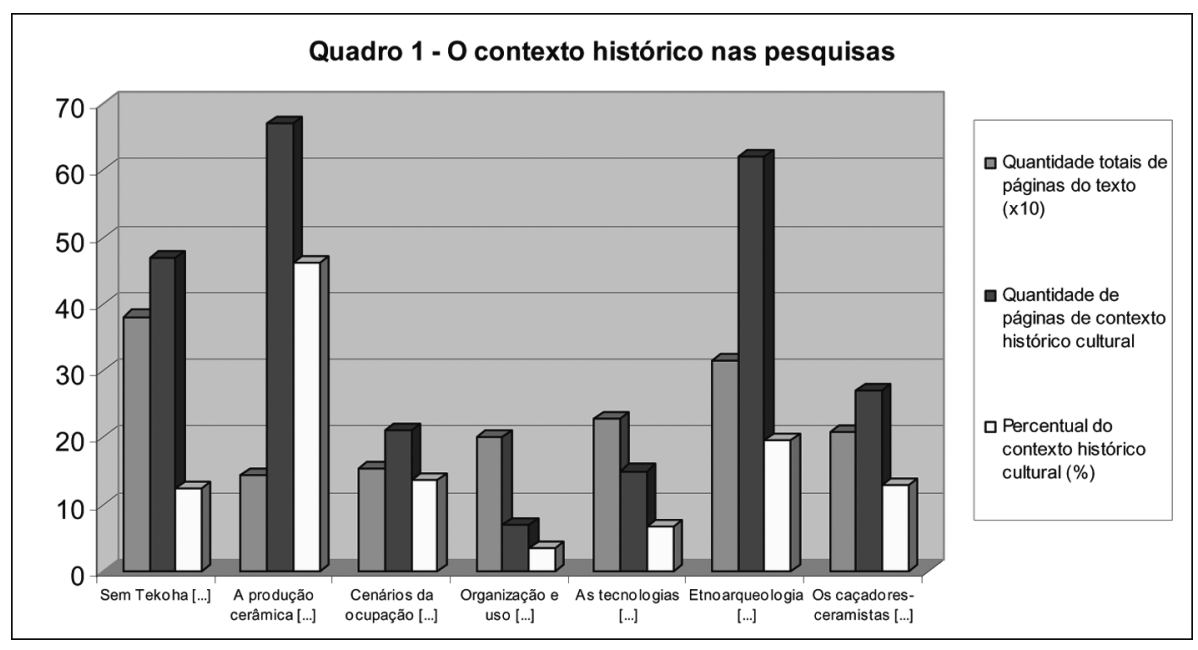


Tabela 1

\begin{tabular}{|c|c|c|c|c|c|}
\hline \multicolumn{6}{|c|}{ Temas de pesquisa e sua distribuição } \\
\hline & $\begin{array}{l}\text { Análise de } \\
\text { material } \\
\text { cerâmico }\end{array}$ & $\begin{array}{c}\text { Padrão de } \\
\text { assentamento }\end{array}$ & $\begin{array}{l}\text { Análise de } \\
\text { cestaria }\end{array}$ & $\begin{array}{l}\text { Estratégias de } \\
\text { subsistência }\end{array}$ & Grafismos \\
\hline $\begin{array}{l}1 \text { Sem Tekoha não há Teko } \\
\text { (em busca de um modelo [...]) }\end{array}$ & & $\mathrm{X}$ & & $\mathrm{X}$ & \\
\hline $\begin{array}{l}2 \text { A produção cerâmica como } \\
\text { reafirmação de identidade [...] }\end{array}$ & $\mathrm{X}$ & & & & \\
\hline $\begin{array}{l}3 \text { Cenários da ocupação Guarani } \\
\text { na calha do Alto Paraná: [...] }\end{array}$ & $\mathrm{X}$ & & & & \\
\hline $\begin{array}{l}4 \text { Organização e uso do espaço } \\
\text { em duas aldeias Xerente: [...] }\end{array}$ & & $\mathrm{X}$ & & & \\
\hline $\begin{array}{l}5 \text { As tecnologias e seus significa- } \\
\text { dos: Um estudo da [...] }\end{array}$ & $\mathrm{X}$ & & $\mathrm{X}$ & & \\
\hline $\begin{array}{l}6 \text { Etnoarqueologia dos grafismos } \\
\text { Kaigang: Um modelo [...] }\end{array}$ & $\mathrm{X}$ & & & & X \\
\hline $\begin{array}{l}7 \text { Os caçadores-ceramistas do } \\
\text { sertão paulista: Um estudo[...] }\end{array}$ & $\mathrm{X}$ & $\mathrm{X}$ & & & \\
\hline
\end{tabular}

Neste ponto, é possível assinalar uma segunda característica marcante das pesquisas em Etnoarqueologia no Brasil: a preferência pelos temas dos povos nativos indígenas. A totalidade dos trabalhos aqui estudados focam seus estudos em aspectos da cultura material de povos indígenas brasileiros.

Tal preferência justifica-se pelos mais variados motivos, desde motivações de cunho pessoal, trabalhos de outros pesquisadores que despertaram interesse pelo tema, contato com tribos indígenas, interesse em conhecer esses povos mais profundamente, até questões de ordem científica, como carência de informações e pesquisas a respeito de determinado povo ou mesmo questões de cunho político e social, como a urgência em estudar determinadas regiões ou povos a serem perturbados por empreendimentos de infraestrutura a serem erigidos em seus locais tradicionais de vivência.

O fato é que parece evidente que o poder analógico da Etnoarqueologia indígena nativa é de importância fundamental não só para a sociedade brasileira, em seu processo de autoconhecimento, a partir dos povos e etnias que a constituem, mas também para os próprios povos estudados, através da visibilidade e do poder de penetração desses estudos na reafirmação de sua identidade, sua importância e seus direitos no interior da comunidade nacional. Entretanto, da mesma forma são de imensa importância para a própria Arqueologia de modo geral.

Entrar em contato com povos que ainda hoje vivem sob lógicas sociais e culturais, em grande parte diversas da cultura homogeneizante da sociedade Ocidental, cada vez mais globalizada, é ter a oportunidade de estabelecer critérios comparativos a respeito da relação entre o homem e o seu meio circundante, do universo ideológico que envolve tal relação e das lógicas inerentes aos processos de produção artefatual humana que ampliem o campo de visão do arqueólogo e que possam propor novas abordagens interpretativas do tempo/espaço que estudam, novas analogias ampliadoras dos múltiplos sentidos, finalidades e funcionalidades dessa produção material.

Por outro lado, é possível perceber ainda, como uma terceira característica da Etnoarqueologia brasileira, a tendência de enquadramento teórico dentro dos horizontes científicos do Pós-Processualismo. Muito embora as discussões de ordem teórica, algumas vezes, não apareçam claramente definidas nos textos, quer em relação às diversas visões 
teóricas da Arqueologia, quer em relação aos diferentes enquadramentos teóricos específicos da Etnoarqueologia, e algumas outras vezes sequer estão claramente definidas as opções teóricas adotadas pelo autor no desenvolvimento de seu estudo, em inúmeros momentos ao longo dos textos lidos, percebe-se a preocupação dos autores em destacar a importância das especificidades culturais e históricas e dos contextos ideacionais, na produção artefatual humana.

Em boa parte dos trabalhos há mesmo como objetivo do próprio estudo buscar compreender relações entre cultura, formas de pensamento, e a produção material dos povos estudados, e, muito embora, nem sempre esses objetivos sejam claramente alcançados, é possível perceber que os autores têm preocupação em discutir a necessidade de ultrapassar a busca por tipologias ou por determinantes ecológicos, no estudo da realidade artefatual dos povos estudados e de perceber os componentes de especificidade, de escolha e de condicionamentos subjetivos no modo de produzir e de viver dessas comunidades (Tabela 2).

Assim, se por um lado, é certo que tais posicionamentos teórico-metodológicos se enquadram dentro dos horizontes e das opções de construção de uma Etno-História que busca valorização cultural, visibilidade social e actuação política em favor dos povos indígenas em território brasileiro; por outro, é também verdade que tal objetivo se encontra muitas vezes com alcance reduzido pelas limitações ressaltadas por vários dos autores analisados, dentre elas: a falta de estudos mais aprofundados e com enfoques mais variados, acerca desses povos.

Entretanto, há que se perceber que, se, por um lado, o recorrer à Arqueologia, à História e à Etnologia, é de importância fulcral para o desenvolvimento de um trabalho em Etnoarqueologia, por ser esta um campo interdisciplinar, e pela riqueza de informações que tais estudos podem trazer ao Etnoarqueólogo, aprofundando seus conhecimentos, e ampliando seus olhares acerca do povo que estuda, por outro, se torna tarefa de grande complexidade e risco, tomar, de textos científicos cuja finalidade e enfoque estão sob diferentes perspectivas teóricas, como documentos acerca de escavações arqueológicas, ou trabalhos de etnologia realizados em sítios referenciados como sendo do mesmo povo que é foco de analise da pesquisa, informações que possam ser interpretadas sob a perspectiva teórica e as finalidades da Etnoarqueologia.

Neste ponto, me refiro à quarta característica desse campo teórico no Brasil: uma ainda

Tabela 2

Enquadramento teórico

\begin{tabular}{|c|c|c|c|}
\hline & Processualista & Contextualista & Não Definido \\
\hline $\begin{array}{l}1 \text { Sem Tekoha não há Teko } \\
\text { (em busca de um modelo [...]) }\end{array}$ & & & $\mathrm{X}$ \\
\hline $\begin{array}{l}2 \text { A produccão cerâmica como } \\
\text { reafirmação de identidade [...] }\end{array}$ & & $\mathrm{X}$ & \\
\hline $\begin{array}{l}3 \text { Cenários da ocupação Guarani } \\
\text { na calha do Alto Paraná: [...] }\end{array}$ & & & $\mathrm{X}$ \\
\hline $\begin{array}{l}4 \text { Organização e uso do espaço } \\
\text { em duas aldeias Xerente: }[. . .]\end{array}$ & & & X \\
\hline $\begin{array}{l}5 \text { As tecnologias e seus significa- } \\
\text { dos: Um estudo da [...] }\end{array}$ & $\mathrm{X}$ & $\mathrm{X}$ & \\
\hline $\begin{array}{l}6 \text { Etnoarqueologia dos grafismos } \\
\text { Kaigang: Um modelo [...] }\end{array}$ & & $\mathrm{X}$ & \\
\hline $\begin{array}{l}7 \text { Os caçadores-ceramistas do } \\
\text { sertão paulista: Um estudo[...] }\end{array}$ & & $\mathrm{X}$ & \\
\hline
\end{tabular}


não total abrangência de trabalhos de campo feitos efetivamente para o estudo e sob as perspectivas da Etnoarqueologia, ou seja, pesquisas de cunho etnográfico, realizadas sob o enfoque teórico Arqueológico, visando observar, compreender e descrever as tramas nas quais se envolve todo o processo de produção artefatual dos povos a serem pesquisados.

Nota-se que, embora a maioria das pesquisas analisadas neste estudo tenham recorrido a trabalho de campo, alguns trabalhos não contaram com esse importante recurso em sua elaboração, sendo realizados tendo como referenciais escavações arqueológicas, ou documentos a esse respeito, e pesquisas em trabalhos de Etnologia e História Indígena, somente (Tabela 3).

Este é por si um dado preocupante porque, se os documentos provenientes de escavações arqueológicas podem fornecer informações a respeitos dos artefatos produzidos por esses povos, não é possível visualizar os atores a produzi-los, seus discursos, seus condicionantes sociais e culturais, todo o processo que envolve o fazer, o fabricar, o pensar acerca desses artefatos e as múltiplas relações existentes entre as condicionantes ecológicas e ideacionais que envolvem todo esse processo.
Por outro lado, a análise dos trabalhos em Etnologia realizados a respeito dos povos cuja Etnoarqueologia procura-se construir, pode descrever-nos a cor da vivência desenvolvida por este povo em relação a si próprio e ao meio no qual se insere. Pode esclarecer a respeito de suas crenças, festas, rituais, condicionantes sociais, relações de poder e muitos outros aspectos, mas raramente o etnólogo tem seu olhar voltado para os processos que culminam em produção material, efectivamente. Se é possível, e mesmo certo, que a produção artefatual desses povos apareça em meio aos aspectos analisados nesses trabalhos, este não é o foco de estudo desses pesquisadores, que têm seu olhar voltado para outras relações e aspectos, e tais descrições têm pouca possibilidade de constituírem material para analogias arqueológicas com a mesma profundidade e riqueza com que uma descrição etnográfica voltada efectivamente para os processos que envolvem a produção artefactual desses povos.

Assim, por um lado se sabe das dificuldades que envolvem um trabalho de campo a ser realizado em comunidades indígenas nativas: as enormes distâncias físicas que, às vezes, separam o pesquisador dessas comunidades, a acessibilidade a elas, quer seja em âmbito local,

Tabela 3

\begin{tabular}{|c|c|c|c|}
\hline \multicolumn{4}{|c|}{ Recurso ao trabalho de campo } \\
\hline & Etnoarqueológico & Arqueológico & Inexistente \\
\hline $\begin{array}{l}1 \text { Sem Tekoha não há Teko } \\
\left(\text { em busca de um modelo }[\ldots . . .)^{*}\right.\end{array}$ & & & $\mathrm{X}$ \\
\hline $\begin{array}{l}2 \text { A produção cerâmica como } \\
\text { reafirmação de identidade [...] }\end{array}$ & $\mathrm{X}$ & & \\
\hline $\begin{array}{l}3 \text { Cenários da ocupação Guarani } \\
\text { na calha do Alto Paraná: [...] }\end{array}$ & & $\mathrm{X}$ & \\
\hline $\begin{array}{l}4 \text { Organização e uso do espaço } \\
\text { em duas aldeias Xerente: [...] }\end{array}$ & $\mathrm{X}$ & & \\
\hline $\begin{array}{l}5 \text { As tecnologias e seus significa- } \\
\text { dos: Um estudo da [...] }\end{array}$ & $\mathrm{X}$ & & \\
\hline $\begin{array}{l}6 \text { Etnoarqueologia dos grafismos } \\
\text { Kaigang: Um modelo }[\ldots]\end{array}$ & $\mathrm{X}$ & & \\
\hline $\begin{array}{l}7 \text { Os caçadores-ceramistas do } \\
\text { sertão paulista: Um estudo[...] }\end{array}$ & $\mathrm{X}$ & & \\
\hline
\end{tabular}

* Esta pesquisa não contou com nenhum tipo de trabalho de campo. 
em relação a própria comunidade, quer seja em âmbito Estatal, os abismos culturais e linguísticos que podem separar o Etnoarqueólogo e o povo a ser estudado, ou até mesmo limitações em relação aos financiamentos necessários para suprir despesas de deslocação e permanência do cientista na área onde inserem-se essas comunidades. Mas sabe-se também da importância do trabalho de campo no desenvolvimento de uma pesquisa em Etnoarqueologia, um desafio que está mesmo na origem dessa própria subdisciplina: a busca de analogias advindas de trabalhos Etnográficos realizados sob uma perspectiva Arqueológica.

Entretanto, por outro lado, não basta que esses trabalhos de campo sejam realizados pelo Etnoarqueólogo, é preciso que o seu desenvolvimento seja rigorosamente descrito e que seja possível "ouvir" no decorrer da leitura do trabalho, os atores a tecerem seus próprios discursos explicativos acerca do que fazem, de como fazem e de porque fazem seus artefatos, de suas opções, de seus condicionantes, de seus próprios motivos e visões a respeito dessa produção. É preciso também que se possa "visualizar" aquilo que o Etnoarqueólogo assistiu em seu trabalho de campo, perceber quando, em que circunstâncias, sob que condições, por quem e por que, as atividades produtivas foram realizadas, deixando claro ao leitor o que é descrição e o que é interpretação do pesquisador durante o trabalho de campo. Por fim, também é preciso conhecer esses atores, quem são, a que posições sociais pertencem, o tipo de relação que estabeleceram com o pesquisador, que têm com a produção artefatual de seu povo, e claro, as relações do próprio pesquisador com esse povo, os motivos que o levaram a pesquisá-lo, seu envolvimento pessoal, seus conhecimentos acerca dele.

Em torno de tal temática é que se insere uma quinta característica da Etnoarqueologia brasileira, apreendida a partir dos textos aqui analisados: a falta de clareza a respeito dos Métodos Etnográficos e da descrição dos trabalhos de campo realizados pelos pesquisadores. Muito embora em alguns poucos trabalhos tais aspectos e procedimentos estejam claramente descritos e identificados, na maioria deles há grandes dúvidas a respeito desses pontos.

Os dados a respeito da amostragem do grupo escolhido para a pesquisa, as estratégias, o número de povoações, famílias ou indivíduos, a sua representação de classes, posições sociais, status, papéis ou géneros, da utilização de assistentes, as qualificações e relacionamento desses com os informantes da comunidade estudada, bem como conhecimentos do investigador, incluindo seus conhecimentos culturais acerca do grupo a ser pesquisado e da sua língua. Raramente essas questões aparecem explicitados nos textos, enquanto as condições de financiamento e a duração do trabalho de campo, embora apareça nos textos, nem sempre são descritas com a clareza e com o destaque que mereceriam.

Assim, na análise das pesquisas, podemos perceber, em parte, suas carências quanto aos aspectos aqui relacionados. Muito embora os dados estudados só contemplem os itens que constam ou não dos trabalhos, excluindo seu grau de clareza, nota-se a falta de atenção dada a tais questões (Tabela 4).

Já quanto a descrição do trabalho de campo, esta aparece, muitas vezes, confundida com as interpretações do próprio autor ou de outros, utilizados como fontes de pesquisa, a respeito dos aspectos analisados no texto. Em raros trabalhos há uma perfeita clareza com relação às partes do texto que constituem descrição de acções observadas ou discursos proferidos pelos informantes ou assistentes que auxiliaram a execução da pesquisa, com devida definição dos atores, e dos contextos que envolvem tais ações ou discursos, ou com a transcrição literal de declarações, histórias, diálogos, devidamente identificados e contextualizados no texto.

Tal preocupação é, entretanto, essencial para que o leitor possa, dessa forma, "visualizar" e “ouvir” os atores, e possa perceber não só em que ponto começa a interpretação do pesquisador acerca do que viu e ouviu, mas também os condicionantes que envolvem essas descrições e declarações.

Assim, é possível não só dar ao leitor a oportunidade de tecer suas próprias interpretações tendo como base as descrições e declara- 
Tabela 4

\begin{tabular}{|c|c|c|c|c|c|}
\hline \multicolumn{6}{|c|}{ Definição do trabalho de campo } \\
\hline & & $\begin{array}{c}\text { Informação sobre a } \\
\text { duração do } \\
\text { trabalho de campo }\end{array}$ & $\begin{array}{l}\text { Dados sobre a } \\
\text { amostragem do } \\
\text { grupo estudado }\end{array}$ & $\begin{array}{c}\text { Informações } \\
\text { sobre língua do } \\
\text { povo estudado }\end{array}$ & $\begin{array}{l}\text { Dados sobre o } \\
\text { financiamen- } \\
\text { to da pesquisa }\end{array}$ \\
\hline & $\begin{array}{l}\text { Sem Tekoha não há Teko } \\
(\text { em busca de um modelo }[\ldots . .])^{*}\end{array}$ & & & & \\
\hline & $\begin{array}{l}\text { A produção cerâmica como } \\
\text { reafirmação de identidade [...] }\end{array}$ & & $\mathrm{X}$ & & \\
\hline 3 & $\begin{array}{l}\text { Cenários da ocupação Guarani } \\
\text { na calha do Alto Paraná: [...] }\end{array}$ & $\mathrm{X}$ & & & $\mathrm{X}$ \\
\hline & $\begin{array}{l}\text { Organização e uso do espaço em } \\
\text { duas aldeias Xerente: [...] }\end{array}$ & $\mathrm{X}$ & & & $\mathrm{X}$ \\
\hline 5 & $\begin{array}{l}\text { As tecnologias e seus significa- } \\
\text { dos: Um estudo da }[\ldots]\end{array}$ & $\mathrm{X}$ & $\mathrm{X}$ & $\mathrm{X}$ & $\mathrm{X}$ \\
\hline 6 & $\begin{array}{l}\text { Etnoarqueologia dos grafismos } \\
\text { Kaigang: Um modelo }[\ldots]\end{array}$ & & & & X \\
\hline 7 & $\begin{array}{l}\text { Os caçadores-ceramistas do } \\
\text { sertão paulista: Um estudo[...] }\end{array}$ & & & & $\mathrm{X}$ \\
\hline
\end{tabular}

* Esta pesquisa não contou com nenhum tipo de trabalho de campo.

ções obtidas em campo, como também perceber, de forma mais clara as percepções e interpretações obtidas pelo pesquisador a partir de tais dados. Além disso, passa a ser possível ponderar as circunstâncias nas quais se inserem as ações descritas e as declarações obtidas, bem como perceber em que posição social se incluem, de forma a gerar dados mais específicos, com maior poder interpretativo em relação às analogias que podem daí surgir.

É evidente, entretanto, que tais ausências não inviabilizam o poder explicativo dos processos produtivos que constituem objetivos dessas pesquisas e que caracterizam somente a opção por uma perspectiva descritiva mais próxima do discurso histórico que propriamente etnográfico ou arqueológico, o que talvez se explica pelo próprio cariz da arqueologia relacionada com os grupos indígenas no Brasil, globalizante, buscando reconstruir uma trajetória cultural e ecológica desses povos num tempo/espaço entrecortado pela colonização européia da América e pelo surgimento da nação brasileira.

Por fim há que se destacar que as ausências e permanências no fazer científico da Etnoarqueologia brasileira aqui discutidos, não só não abarcam a totalidade das características desse campo científico no Brasil, uma vez que a ciência é feita por um grupo específico com lógicas próprias; mas que é, por sua vez, formada por pessoas singulares, com visões particularmente únicas da ciência e do mundo. Princípio que se aplica não só aos investigadores, mas também àqueles que lêem seus escritos e os interpretam, não significando críticas à forma como tal campo científico se desenvolve nesse país, tão somente procura caracterizar a Etnoarqueologia aqui praticada,dentro das possibilidades e opções nas quais se insere não só a Arqueologia, mas toda a sociedade brasileira contemporânea.

\section{Conclusões: Horizontes científico-sociais da etnoarqueologia no Brasil (ou da necessidade de convertibilidade do outro)}

Joaquin Herrera Flores, em seu artigo intitulado "Colonialismo y violencia. Bases para una reflexión pos-colonial desde los derechos humanos" (2006), nos alerta acerca da empresa colonizadora Ocidental e de seu método de ação em relação aos povos com os quais entra em contacto. 
Segundo ele, a nossa sociedade produz diante do "outro", uma reacção de "backlash", que possui dois intentos fundamentais: a construção de uma identidade abstrata, afastada de quaisquer origens históricas ou políticas concretas (ocultar nosso multiculturalismo) e a invenção de origens identitárias que não se contraponham aos interesses e medos do presente (ocultar a possibilidade de descobrirmos em nós, o "outro").

Esta reação se torna o substrato a partir do qual construímos a idéia de nossa superioridade cultural e encontramos justificativa para a intervenção na demais culturas. Isso porque, na medida em que não nos enxergamos como multiculturais, que não nos vemos no "outro", mas participantes de uma cultura abstracta, não compreendemos o modo de vida "deles" e nos achamos no direito de interferir em outros povos de forma a expandir nossa própria cultura e sufocar suas "estranhas" formas de viver e de pensar. Mesmo que isso signifique protestos, desespero, doenças e mortes, no interior dessas sociedades, estamos prontos a pôr em prática nosso aparato "humanitário" para curar as feridas que produzimos, e assim, nos sentimos ainda mais superiores, e não somos capazes de compreender a negativa de certos povos em aceitar tantos benefícios que a eles concedemos (Flores 2006:25-26).

A respeito dessa questão o autor traça uma analogia riquíssima:

"Estamos como aquellos indígenas amazónicos o aquellos esquimales canadienses que a causa de las continuas invasiones de sus territórios por occidentales cayeron enfermos de males hasta entonces desconocidos por su chamanes. A partir de ahi de nada valian los conocimientos tradicionales; solo podían curarse acudiendo a la medicina y a los hospitales de aquellos que les habíam introducido la enfermedad." (Flores 2006:26).

(2) "backlash" - A strong but usu. delayed feeling of opposition among many people toward a belief or practice, esp. towards a political or social development (...) a sudden violent backward movement (Longman Dictionary of Contemporary English, 1992).
Ora, os indígenas brasileiros continuam a sofrer desses mesmos males ainda hoje. Ao terem seu modo de vida drasticamente transformado a partir da colonização européia da América, e seu espaço progressivamente ocupado por outra cultura radicalmente diferente das suas, vêem-se cada vez mais sujeitos à necessidade de protestarem, segundo as regras estabelecidas pela sociedade dominadora, a fim de garantirem, segundo as leis do Estado Nacional dentro do qual habitam, a posse e o uso das terras que tradicionalmente ocuparam, bem como o direito a um tipo de educação voltado para suas expectativas e necessidades, e de viverem segundo suas próprias lógicas e crenças.

A Etnoarqueologia, como ciência que busca alcançar conhecimento arqueológico através de estudos de cunho etnográfico, não pode se abster do fato de que além de construir conhecimentos abstractos a respeito da trajetória humana e de sua produção artefatual/ cultural, está a tratar de questões que dizem respeito à história e à cultura de povos contemporâneos, que podem ter nessas informações, subsídios para a defesa dos direitos que buscam alcançar na sociedade nacional.

Neste ponto a Etnoarqueologia brasileira não tem se posto a parte das urgências das questões por ela levantadas a respeito dos povos indígenas brasileiros, e se mantém fortemente presente, no decorrer das pesquisas aqui analisadas, não só para denunciar as situações de dominação e de colonização sofridas pelos povos pesquisados no decorrer de suas histórias, como as necessidades e reivindicações desses povos no presente.

Mas novas contingências apontam para o alargamento dos horizontes desse campo científico no Brasil. Outros grupos étnicos, que também constituem comunidades em maior e em menor grau afastadas das lógicas culturais da sociedade ocidental, e que, também possuem grande potencial científico, na busca de analogias arqueológicas, bem como grande potencial sóciopolítico, participantes na trama étnico-cultural que constitui o povo brasileiro, tomam cada vez mais visibilidade no cenário nacional e despertam a atenção para o estudo de suas trajetórias 
históricas e culturais e para o discutir de suas lógicas, visões de mundo e reivindicações.

Em particular, destaca-se a importância das comunidades Quilombolas no alertar para o reescrever de uma história que não aponta somente para a dominação e a escravidão de povos africanos no Brasil, mas também para formas de luta e de resistência, na tentativa de preservação de um modo de vida alternativo às imposições das elites dominantes.

Por outro lado, a análise de Joaquín Herrera Flores acerca de nossa visão cultural homogénea sobre nós mesmos e sobre os outros, incapaz de ver os multiculturalismos presentes em qualquer comunidade humana e cegos tanto para os nossos defeitos quanto para as qualidades do "outro" no conviver com grupos culturais diferentes, toma uma dimensão importante em duas vertentes.

Em termos de posicionamento ético, que não só desafia cientistas de todas as áreas, mas toda a sociedade, a desenvolver um olhar polissémico acerca do "outro", que seja capaz, não só de relativizar nossos próprios princípios e visões acerca do mundo - de perceber que não são os únicos possíveis, e que não são homogéneos, mesmo no interior da nossa sociedade - mas também de perceber que os modos de viver diferentes das outras sociedades, não significam que essas sejam inferiores, exóticas ou desprezíveis, mas que são outras visões, igualmente válidas e com valor equiparável às nossas próprias, e que, para além disso, essas outras sociedades também não são, elas próprias, homogéneas, e que há diferenças no interior de todos os grupos humanos.

Em termos de posicionamento científico, oferece ao Etnoarqueólogo um desafio e uma importante crítica: é preciso estar atento para o fato de que o seu trabalho não deve servir de substrato para esse tipo de homogeneização cultural e que o olhar desse cientista deve estar sempre preparado para observar os povos que estuda, não só pela perspectiva das tipologias, dos fósseis-diretores, enfim, das semelhanças e permanências; mas também para perceber as culturas que estuda, como elementos que são compostos de pluralidades e que se transformam no tempo.
Acerca disso, fala-nos Solange Schiavetto, em seu livro "A arqueologia Guarani. Construção e desconstrução da identidade indígena":

"Não se trata de simplesmente desvincular cultura material e grupos étnicos, dizendo, por exemplo, que os Guarani pré-históricos nada têm a ver com os Guarani conhecidos ou com os atuais (...) Tratar-se, ao contrário, de aceitar a possibilidade de os grupos étnicos serem vistos como entidades dotadas de um carácter situacional e fluido, repensando as tradições e subtradições utilizadas na arqueologia até o momento" (Schiavetto 2003:101).

Ora, tal questão não abarca somente a Cultura Guarani, mas todas as culturas estudadas cientificamente, bem como a Cultura daqueles que as estudam, e é preciso que tenhamos o cuidado de perceber tais questões, mesmo que elas nos levem a repensar os objetivos de nossos trabalhos, a buscar novas vias e novos questionamentos, que nos levem a ampliar os olhares e os horizontes dos estudos que se referem a grupos étnicos em todas as partes do mundo, e em especial, no Brasil.

Trata-se de abordar, nos estudos étnicos, entre os quais os Etnoarqueológicos, a fluídez de todas as culturas, sua não homogeneidade quer interna, quer histórica - e ver a cultura sob uma perspectiva mais humanizada, mais atenta a própria natureza humana em seu viés auto-transformador e por isso mesmo também transformador do ambiente - quer físico, quer social - no qual se insere. Acerca disso ainda nos fala Schiavetto:

"Ao definir uma "cultura arqueológica" com base nos traços materiais das sociedades indígenas, cria-se por meio da delimitação conceitual, categorias imutáveis, seguindo padrões de vida social (assentamento, religião, adaptação ao meio, confecção de cultura material) cujas variantes culturais acabam por ser "mascaradas pela busca de uma grande nação guarani” (...) Dessa forma, o guarani foi, no decorrer da história do 
pensamento arqueológico, incessantemente criado por arqueólogos (...)” (Schiavetto 2003:119).

\section{É claro que não se trata de desvalorizar a} importância das categorias para a Arqueologia e para o estudo do Homem em sua relação com seu meio circundante, tanto humano quanto natural, tanto quanto também não se trata de esquecermos que, em última instância, qualquer estudo é uma construção, uma visão de um cientista e de uma ciência acerca de seu objecto, e que independente da abrangência e do enfoque escolhido, o discurso que se constrói acerca dele nunca abrangerá a sua complexidade por completo.

Trata-se, entretanto, de termos a consciência de que as categorias que escolhemos analisar nos trabalhos em Arqueologia, e em especial nos estudos Etnoarqueológicos, não podem servir para subjugar as diferenças, ou para ignorá-las, obrigando o quotidiano estudado a forçosamente ser compatível com as categorias estudadas, quando nos deparamos com situações que ponham em questão nossas escolhas e classificações, mas de admitirmos que as teorias, métodos e técnicas que usamos nos trabalhos científicos são somente opções de análise e ângulos de visão de uma realidade cuja complexidade nunca poderá ser completamente percebida, e de que não podemos sujeitar essa complexidade às nossas opções de análise quando a realidade nos impõe que nossas opções sejam reavaliadas, ou que simplesmente possamos admitir nossos limites na análise de determinado objeto.
Enfim, que tenhamos como horizonte teórico e social da Etnoarqueologia brasileira, o compromisso de contribuirmos, para, nas palavras de Cornelius Castoriadis, apreendidas por Joaquín Herrera Flores, combater "a essencial inconvertibilidade do Outro" (Flores 2006:34), ou seja, superarmos uma visão estreita das outras culturas, que nos impede de nos convertermos nos "outros" ou de convertêlos em nós mesmos, de percebermos o quanto nenhuma cultura é homogénea ou superior, de quão multicultural e polissémico todos nós somos, e como as estranhezas de outras culturas se aproximam das nossas próprias, e de, assim, podermos fazer uma ciência mais próxima do cotidiano que a inspira e a constitui, quer através de seus agentes, quer através dos seus objetos.

\section{Agradecimentos}

O problema central deste artigo relaciona-se às perspectivas abordadas em minha dissertação de Mestrado, defendida em Maio de 2008 na Universidade do Algarve, Portugal, e resultado de uma cooperação entre esta Universidade, através da orientação do Prof. Dr. Nuno Bicho, e da UNICAMP, através da orientação do Prof. Dr. Pedro Paulo Abreu Funari, aos quais agradeço profundamente pela constante disponibilidade e pelos importantes direcionamentos nesta minha incursão pelos horizontes científicos da Etnoarqueologia. 
POLONI, R.J.S. The Ethnoarchaeology in Brazil: science and society in the context of the re-democratization. Revista do Museu de Arqueologia e Etnologia, São Paulo, 19: 87-102, 2009.

Abstract: The present work was to investigate the theoretical and methodological perspectives used in scientific texts in Ethnoarchaeology, published in Brazil from the decade of 1980. The focus of this study was MA thesis and PH dissertations, to obtain information on the employed methodologies and the theoretical field, as well as constructing a picture of penetration of this scientific field in Brazil. Was possible to realize their strong historic and politic focus and their preferential treatment for generic methodologies and techniques in the analysis of their study objects.

Keywords: Archaeology - Ethnoarchaeology - Theory - Methods - Society - Brazil.

\section{Referências bibliográficas}

AULETE, C.

2007 Indigena. In Aulete, C. Aulete digital Dicionário contemporâneo da língua portuguesa: Dicionário Caldas Aulete, versão on-line, acessado em 15 de julho de 2007.

BINFORD, L.

1978 Nunamiut Ethnoarchaeology. New York: Academic Press.

DAVID, N.; KRAMER, C.

2001 Ethnoarchaeology in Action. Cambridge: Cambridge University Press.

2002 Teorizando a Etnoarqueologia e a Analogia. Horizontes Antropológicos, 18:13-60.

FERREIRA, A.G.

1996 Dicionário de Português-Latim. Porto: Porto Editora.

FLORES, J.H.

2006 Colonialismo y violencia. Bases para una reflexión pos-colonial desde los derechos humanos. Revista critica de ciências sociais, 75: 21-40.

HODDER, I.

1985 Postprocessual Archaeology. In Schiffer, M (Ed.) Advances in Archaeological Method and Theory, 8: 1-16.

\section{LONGMAN}

1992 Indígena. In: LONGMAN. Longman Dictionary of Contemporary English. England: Longman-Group Limited.
MOI, F.P.

2003 Organização e Uso do Espaço em duas Aldeias Xerente: Uma Abordagem Etnoarqueológica. Museu de Arqueologia e Etnologia da Universidade de São Paulo (MAE/USP). Dissertação de Mestrado

NOELLI, F.S.

1993 Sem Tekohá não há Tekó: Em Busca de um Modelo Etnoarqueológico da Aldeia e da Subsistência Guarani e sua Aplicação a uma Área de Domínio no Delta do Rio Jacui-RS. Pontifícia Universidade Católica do Rio Grande do Sul (PUC - RS). Dissertação de Mestrado.

OLIVEIRA, L.M.

1999 A Produção Cerâmica como Reafirmação de Identidade Étnica Maxakali: Um Estudo Etnoarqueológico. Universidade de São Paulo (USP). Dissertação de Mestrado.

POLITIS, G.G.

2002 Acerca de la Etnoarqueología en América del Sur. Horizontes Antropológicos, 18: 61-91.

RODRIGUES, R.A.

2001 Cenários da Ocupação Guarani na Calha do Alto Paraná: um Estudo Etnoarqueológico. MAE-USP. Dissertação de Mestrado.

2007 Os caçadores Ceramistas do Sertão Paulista: Um Estudo Etnoarqueológico da Ocupação Kaingang no Vale do Rio Feio/Aguapeí. MAE-USP. Tese de Doutorado. 
A Etnoarqueologia no Brasil: ciência e sociedade no contexto da redemocratização.

Revista do Museu de Arqueologia e Etnologia, São Paulo, 19: 87-102, 2009.

\section{SCHIAVETTO, S.N.O.}

2003 A arqueologia Guarani. Construção e desconstrução da identidade indígena.São Paulo: Annablume editora.

SILVA, F.A.

2000 A Tecnologia e seus Significados. Um Estudo da Cerâmica dos Asurini do Xingu e da Cestaria dos Kayapó-Xikrin sob uma Perspectiva Etnoarqueológica. Universidade de São Paulo. Tese de Doutorado.

SILVA, S.B.D.

2001 Etnoarqueologia dos Grafismos Kaigang: Um Modelo para a Compreensão das Sociedades Proto-Jê Meridionais. Universidade de São Paulo. Tese de Doutorado.

Recebido para publicação em 28 de fevereiro de 2009. 